\title{
Vegetation dynamics of abandoned paddy fields and surrounding wetlands in the lower Tumen River Basin, Northeast China
}

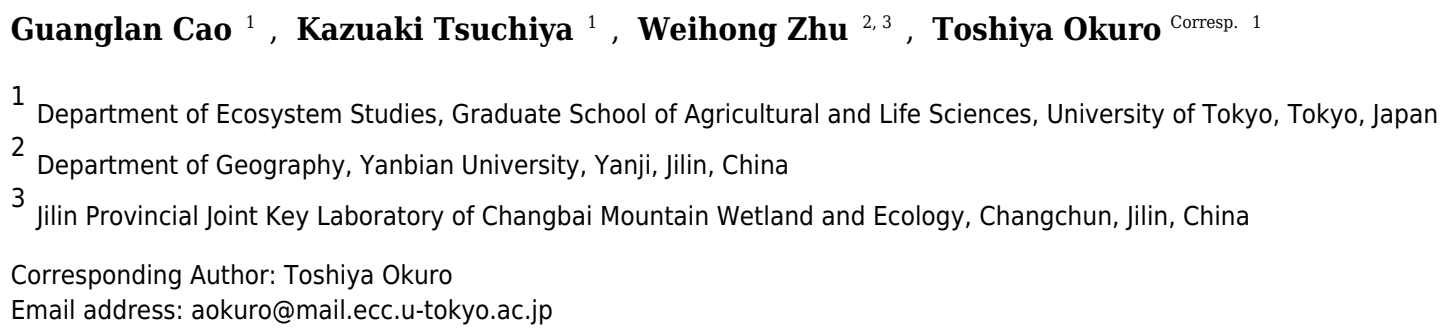

On the temperate lowland plain of the lower Tumen River, agricultural development has converted most marshland into paddy fields. However, the locations of old paddy fields in the lowland temperate zone, where the vegetation structure is dominated by herbs adapted to seasonally wet or waterlogged conditions, are poorly known, and the impact of land use history on marshland diversity and shifts in plant functional groups has been scantly researched. In this study, we used a chronosequence approach to investigate herbaceous wetland communities in different recovery phases ( $<5$ years, 5-15 years, and $>15$ years), as well as natural wetland as a reference. We assessed their ecological characteristics, species composition and diversity to determine how they change during natural succession. Plant species composition and dominance in the abandoned fields changed markedly during natural secondary succession. Initially, the annual weeds Echinochloa crus-galli and Bidens tripartita were dominant. Later, communities gradually became dominated first by Polygonum thunbergii and then by tussock-forming Carex rostrata. Species diversity was higher in abandoned fields than in natural wetlands and decreased with time. The partition of $\beta$-diversity components revealed that replacement was the prominent process structuring plant communities in paddy field at different times since abandonment. Our results suggest that the vegetation of abandoned paddy fields could be restored effectively through natural succession, although there were some differences in plant functional group traits. Abandoned paddy fields may be good sites for restoration of wetland species and conservation of wetland habitat. 
1 Vegetation dynamics of abandoned paddy fields and 2 surrounding wetlands in the lower Tumen River Basin, 3 Northeast China

4 Guanglan $\mathrm{CaO}^{1}$, Kazuaki Tsuchiya ${ }^{1}$, Weihong Zhu ${ }^{2,3}$, Toshiya Okuro ${ }^{1}$

$5{ }^{1}$ Department of Ecosystem Studies, Graduate School of Agricultural and Life Sciences, University of

6 Tokyo, Tokyo, Japan

$7 \quad 2$ Department of Geography, Yanbian University, Yanji, Jilin, China

83 Jilin Provincial Joint Key Laboratory of Changbai Mountain Wetland and Ecology, Changchun, Jilin,

9 China

10

11 Corresponding Author:

12 Toshiya Okuro ${ }^{1}$

13 Department of Ecosystem Studies, Graduate School of Agricultural and Life Sciences, The University of 14 Tokyo, 1-1-1 Yayoi, Bunkyo-ku, Tokyo 113-8657, Japan.

15 Email address: aokuro@mail.ecc.u-tokyo.ac.jp 
16 Vegetation dynamics of abandoned paddy fields and

17 surrounding wetlands in the lower Tumen River Basin,

18

19

20

21

22

23

24

25

26

27

28

29

30

31

32

33

34

35

36

37

38

39

40

41

42

43

44

45

46

47

48

49

50

51

52

\title{
Northeast China
}

\author{
Guanglan $\mathrm{Cao}^{1}$, Kazuaki Tsuchiya ${ }^{1}$, Weihong $\mathrm{Zhu}^{2,3}$, Toshiya Okuro ${ }^{1}$ \\ ${ }^{1}$ Department of Ecosystem Studies, Graduate School of Agricultural and Life Sciences, \\ University of Tokyo, Tokyo, Japan. \\ 2 Department of Geography, Yanbian University, Yanji, Jilin, China. \\ 3 Jilin Provincial Joint Key Laboratory of Changbai Mountain Wetland and Ecology, Changchun, \\ Jilin, China.
}

Corresponding Author:

Toshiya Okuro ${ }^{1}$

Department of Ecosystem Studies, Graduate School of Agricultural and Life Sciences, The University of Tokyo, 1-1-1 Yayoi, Bunkyo-ku, Tokyo 113-8657, Japan.

Email address: aokuro@mail.ecc.u-tokyo.ac.jp

\section{Abstract}

On the temperate lowland plain of the lower Tumen River, agricultural development has converted most marshland into paddy fields. However, the locations of old paddy fields in the lowland temperate zone, where the vegetation structure is dominated by herbs adapted to seasonally wet or waterlogged conditions, are poorly known, and the impact of land use history on marshland diversity and shifts in plant functional groups has been scantly researched. In this study, we used a chronosequence approach to investigate herbaceous wetland communities in different recovery phases ( $<5$ years, $5-15$ years, and $>15$ years), as well as natural wetland as a reference. We assessed their ecological characteristics, species composition and diversity to determine how they change during natural succession. Plant species composition and dominance in the abandoned fields changed markedly during natural secondary succession. Initially, the annual weeds Echinochloa crus-galli and Bidens tripartita were dominant. Later, communities gradually became dominated first by Polygonum thunbergii and then by tussock-forming Carex rostrata. Species diversity was higher in abandoned fields than in natural wetlands and decreased with time. The partition of $\beta$-diversity components revealed that replacement was the prominent process structuring plant communities in paddy field at different times since abandonment. Our results suggest that the vegetation of abandoned paddy fields could be restored effectively through natural succession, although there were some differences in plant functional group traits. Abandoned paddy fields may be good sites for restoration of wetland species and conservation of wetland habitat. 


\section{Introduction}

54 Wetlands are among the world's most productive and valuable ecosystems (Mitsch \& Gosselink,

55

56

57

58

59

60

61

62

63

64

65

66

67

68

69

70

71

72

73

74

75

76

77

78

79

80

81

82

83

84

85

86

87

88

89

90

2015; Kennedy \&Mayer, 2002). They are important habitats for a variety of flora and fauna, and are vital ecosystems that provide diverse services. They not only are essential for ecological functions such as maintaining biodiversity, controlling floods, and removing pollutants, but also serve necessary economic functions in rice and fish production, transport, and hydropower energy (Costanza et al., 1997; Mitsch \& Gosselink, 2015; Zedler \& Kercher, 2005). Despite this, they have suffered a loss of $54 \%-57 \%$ of their area worldwide, which continues to be under pressure from agriculture, urban expansion, industrialization, and resource extraction (Davidson, 2014; Zedler \& Kercher, 2005).

China, with $10 \%$ of the world's wetland area, has suffered great losses and degradation, largely attributed to agricultural intensification, severe population pressure, and misguided policies (An et al., 2007; Wang et al., 2012; Sun et al., 2006). Effective protection and restoration of damaged and degraded wetlands is becoming more and more urgent.

Abandoned paddy fields provide opportunities to restore wetlands and serve as substitute habitats for wetland species (Lee et al., 2002; Kusumoto et al., 2005; Takanose et al., 2013; Yamanaka et al., 2017). They may be good sites for restoration of wetlands and conservation of wetland habitats (Cho et al., 2018).

Natural restoration of vegetation in abandoned paddy fields is an example of secondary succession (Cramer \& Hobbs, 2007). Most studies have focused on large-scale farmland, upland fields, and tropical and subtropical areas (Lee, 2006). Few studies have focused on secondary succession of old paddy fields in the lowland temperate zone, where the vegetation structure is dominated by herbs (grasses, sedges, and forbs) adapted to seasonally wet or waterlogged conditions. Thus, our understanding of temperate lowland ecological communities is limited.

The lower Tumen River is situated on the lowland plains of temperate north-eastern China, which have vast natural, wetland-dominated, seasonal herbaceous communities, which serve as important migratory routes for water birds (Brinson \& Malvarez, 2002). Since the 1980s, conversion of wetlands to paddy fields or fishery ponds has eradicated more than half of the area (Zheng et al., 2017). Alterations to the hydrological regime and development are the major threats to this ecosystem and can lead to habitat destruction and shifts in community function.

Here, we selected abandoned paddy wetlands dominated by seasonal herbaceous communities at different recovery phases and assessed their species composition, species diversity and plant functional groups to determine how they change over time. The objectives were (1) to determine whether the abandoned paddy fields were self-regenerating; (2) to assess their stage of secondary succession and how long it took to restore vegetation; and (3) to investigate vegetation succession patterns in abandoned paddy fields.

\section{Materials \& Methods}

\section{Study sites}


91 The study area is located in the lower Tumen River Basin, in north-eastern Jilin Province, China $92\left(42^{\circ} 25^{\prime} 20^{\prime \prime}-43^{\circ} 30^{\prime} 18^{\prime \prime} \mathrm{N}, 129^{\circ} 52^{\prime} 00^{\prime \prime}-131^{\circ} 18^{\prime} 30^{\prime \prime} \mathrm{E}\right.$; 5-15 m a.s.l), and covers the

93 international boundaries between China, North Korea, and Russia (Zhu et al., 2012). The area 94 has a mean annual temperature of $5.65^{\circ} \mathrm{C}$, a maximum monthly average of $21.2^{\circ} \mathrm{C}$ in August, 95 and a minimum monthly average of $-11.7^{\circ} \mathrm{C}$ in January. Mean annual precipitation is $606.8 \mathrm{~mm}$, 96 of which approximately $70 \%$ falls during June-September (Kang et al., 2017).

97 This area has a diverse array of wetlands totalling $8054 \mathrm{~km}^{2}$ (Cui \& Yang, 2002). The Tumen

98 River Basin is characterized by a typical temperate monsoon climate zone and is usually

99 inundated seasonally by rain, and then dries out (Gao et al., 2000).

\section{Survey design}

101

102

103

104

105

106

107

108

109

110

111

112

113

114

115

116

117

118

119

120

121

122

123

124

125

126

127

128

129

We used a chronosequence approach to investigate herbaceous wetland communities during secondary succession in recovery phases of $<5$ years, 5-15 years, and $>15$ years since the last cultivation. A natural wetland region was selected on the lower Tumen River. Since it was difficult to find an undisturbed natural wetland as a reference site, we chose a less disturbed one that had been uncultivated for more than 40 years. Information on the age of abandoned sites was collected via interviews with land owners and village heads. All sites were flat and subject to similar hydrological conditions (Guo et al., 2017).

\section{Vegetation sampling}

To gather comprehensive information on the wetland vegetation, we surveyed vegetation by using the plot method and quadrat method (Magee et al., 1999; Ruto et al., 2012). We located twenty six $100 \mathrm{~m}^{2}$ plots with different phases of succession, and randomly selected five $1 \mathrm{~m}^{2}$ quadrats within each plot. To avoid spatial autocorrelation between plots, the plots were separated by at least $1000 \mathrm{~m}$, but remained within the same general landscape position. Each site was surveyed once during August 2016, the peak growing season in the region. We recorded species composition, species density, species coverage, plant height, water depth, latitude and longitude, wetland type, and habitat details at a total of 130 quadrats. We used species richness (the number of species in each quadrat) as a measure of plant diversity and recorded the abundance of individual species within each quadrat. The scientific names of all vascular plant species complied with the Y List based on APG (http://ylist.info/, queried in November 2014; Japanese names) and with a Chinese database (http://www.plant.csdb.cn/; Chinese names).

\section{Data analysis}

\section{Plant diversity analysis}

We calculated four species diversity indices: Margalef's index of species richness R, ShannonWiener diversity index H, Simpson's index of diversity D, and Pielou's evenness index J (Krebs, 1989). All have low to moderate sensitivity to sample size and are widely used (Alsterberg et al., 2017; Cao \& Zhang, 1997; Magurran, 1988).

\section{Margalef's index of species richness, $R$}

Margalef's $\mathrm{R}$ is a simple measure of species richness (Margalef, 1958):

$$
\mathrm{R}=\text { number of individuals of a species }
$$


130

131

132

133

134

135

136

137

138

139

140

141

142

143

144

145

146

147

148

149

150

151

152

153

154

155

156

157

158

159

160

161

162

163

164

\section{Shannon-Wiener diversity index, $H$}

The $\alpha$-diversity of species within a community or habitat was calculated as the Shannon-Wiener diversity index (Shannon and Weaver 1949):

$$
\mathrm{H}=-\sum_{i=1}^{s} p_{i} \log p_{i}
$$

where $p_{i}=\mathrm{s} / \mathrm{n}, \mathrm{s}=$ number of individuals of a species, $\mathrm{n}=$ total number of individuals in the sample, and logarithm is in base e.

\section{Simpson's index of diversity, $D$}

Simpson's D was calculated as:

$$
\mathrm{D}=1-\sum_{i=1}^{S} p_{i}{ }^{2}
$$

\section{Pielou's evenness index, $J$}

Pielou's J indicates the evenness of species (Pielou, 1966):

$$
\mathrm{J}=\mathrm{H} / \ln \mathrm{S}
$$

where $\mathrm{H}=$ Shannon-Wiener diversity index and $\mathrm{S}=$ total number of species in the sample.

\section{Replacement, richness difference and nestedness indices}

The SDR simplex approach was used to estimate the relative importance of $\beta$-diversity components and similarity by partitioning the pairwise gamma diversity into three components (Podani and Schmera, 2011). Abundance (i.e., cover) data was used to calculate Ružička similarity (S), abundance replacement (R), and abundance difference (D) by the SDRabunSimplex programme (Podani et al., 2013). The SDR results were graphed with a ternary plot using the Ternary Plot option in the NonHier routine of the SYN-TAX 2000 package (Podani, 2001). In the ternary plot, each vertex corresponds to one index (S, D, or R).

\section{Statistical analyses}

For statistical analyses we defined wetland species (W) as those that usually occur in wetland, marshland, ponds, or rice fields, on shorelines, or under water, and non-wetland species (NW) as those without any description of wetland habitat.

Raunkiaer's life-forms were used to categorize plant species as follows (Raunkiaer, 1934): hydrophyte $(\mathrm{HH})$, hydrophyte therophyte $(\mathrm{HH}(\mathrm{Th}))$, hemicryptophyte $(\mathrm{H})$, therophyte $(\mathrm{Th})$, therophyte (winter annual) $(\mathrm{Th}(\mathrm{w}))$, geophyte $(\mathrm{G})$, and chamaephyte $(\mathrm{Ch})$.

Patterns of chorological spectra were quantified at species level and categorized as Cosmopolitan, Holarctic, Palaearctic, Afrotropical, Oriental, or Australian (Takhtajan, 1986).The Holarctic region comprises two subregions: Palaearctic (Europe, Asia north of the Himalayas, and northern Africa) and Nearctic (North America excluding southern Florida, and Greenland (Katinas et al., 1999).

For illustrating wetland patterns and the floristic relationship with sites, ordination methods are more appropriate than clustering when the sites come from different land use forms. 
165 Therefore, we assessed variations in plant species composition and distribution patterns among

166

167

168

169

170

171

172

173

\section{Results}

175

176

177

178

179

180

181

182

183

184

185

186

187

188

189

190

191

192

193

194

195

196

197

198

199

200

201

202

vegetation communities using detrended correspondence analysis (DCA) ordination based on community coverage. To examine the changes in the different functional groups during succession, plant species were grouped according to life form (grass, sedge and forb) to represent structural traits that can influence restoration of wetland (Taft, 2014). Statistical analyses were performed in R software. The diversity indices and DCA were analysed in the R package 'vegan' (Oksanen et al., 2017). One-way analysis of variance (ANOVA) was used to compare the different species diversity index. The Tukey-Kramer procedure followed the ANOVA for the post hoc comparison at $\alpha=0.05$.

\section{Species composition and chorological spectra}

Across all study sites, we recorded a total of 103 species in 68 genera in 34 families (Appendix A). There were 69 wetland species and 34 non-wetland species (Appendix A). All numbers decreased gradually with time since abandonment (Table 1).

At sites abandoned $<5$ years prior, we recorded 62 species. Dominant species were mainly the lowland paddy weeds Echinochloa crus-galli, Bidens tripartita and Arthraxon hispidus.

At sites abandoned 5-15 years prior, we recorded 41 species. Dominant species included the annual species Polygonum thunbergii, and Murdannia keisak and the perennial species Glyceria spiculosa and Scirpus orientalis.

At sites abandoned $>15$ years prior, we recorded 34 species. Dominant species included perennial wetland species such as $C$. rostrata, C. vesicaria, Phragmites australis and $G$. spiculosa. The species composition was consistent with that in natural wetlands.

In the natural wetlands we recorded 37 species. Dominant species included the perennial species C. rostrata, S. orientalis, G. spiculosa and Zizania latifolia and the annual species Salvinia natans and $P$. thunbergii. The chorological spectrum is the geographical distribution of plant species. The chorological spectrum composition of plant species in our study was analyzed from the proportional distribution of chorological types in the spectrum (Fig. 1 and Table S1). The most common chorological type in the lower Tumen River Basin was Palaearctic, which accounted for $40.3 \%$ to $48.8 \%$ of species among sites (Fig. 1 and Table S1). The next most common type was Holarctic, with $22.6 \%$ to $29.2 \%$ of species. Other types were only rarely present and their proportion didn't exceed $20 \%$.

\section{Species richness, diversity and evenness}

Species richness and diversity were highest at $<5$ years since abandonment and declined with time, and were lowest in natural wetlands (Fig. 2 and Table S2). Margalef's R was significantly greater at $<5$ years than later and than in natural wetlands ( $\mathrm{P}<0.001)$ (Fig. $2 \mathrm{~A}$ and Table $\mathrm{S} 2$ ). Shannon's H and Simpson's D were both non-significantly greater at $<5$ years than in natural wetlands (Fig. 2B, 2C and Table S2). However, Pielou's J did not change with succession (Fig. 2D and Table S2). 


\section{SDR analysis and DCA ordination}

204 SDR-simplex analyses showed that the point patterns are concentrated on the top side of the 205 triangles in the different abandoned paddy fields (Fig. 3 and Table S3). In paddy fields at 206 different times since abandonment had a high abundance replacement (R), and low Ružička 207 similarity (S) and abundance richness difference (D). This suggests that plant communities in 208 lowland marsh-type wetland, abundance replacement was the main component $(\mathrm{R}(\mathrm{A})=83.01 \%$; $209 \mathrm{R}(\mathrm{B})=79.86 \% ; \mathrm{R}(\mathrm{C})=77.06 \%$ ) with relatively high values of $\beta$-diversity indicated by a low 210 proportion of Ružička similarity $(\mathrm{S}(\mathrm{A})=6.01 \% ; \mathrm{S}(\mathrm{B})=6.98 \% ; \mathrm{S}(\mathrm{C})=11.54 \%)$. In addition, 211 contributions of abundance richness difference $(D(A)=10.98 \% ; D(B)=13.17 \% ; D(C)=11.40 \%)$

212 were similar to that of compositional similarity. Accordingly, in paddy fields at different times 213 since abandonment had the high richness agreement $(\mathrm{S}+\mathrm{R})$ and $\beta$-diversity $(\mathrm{R}+\mathrm{D})$ and a low 214 nestedness (S + D) (Fig 3 and Table S3)

215 In the DCA ordination based on the vegetation coverage data, Eigenvalues of axes 1 and 2 216 were 0.8689 and 0.7182 , respectively (Fig.4 and Table S4). Natural wetlands and older 217 abandoned rice fields were located to the left of axis 1, and younger ones to the right. Sites 218 tended to be clustered in relation to time since abandonment.

\section{Characteristics of plant functional groups}

220 While herbs were ubiquitous, we recorded no shrubs or woody species. The vegetation 221 community was dominated by a ground layer of forbs, sedges and grasses. The proportion of 222 forb species in abandoned paddy fields and natural wetlands was higher than other plant 223 functional groups (Fig.5A and Table S5).The proportion of grass species in natural wetland was 224 higher than that in abandoned paddy fields and increased with time since abandonment. The 225 proportion of sedge and rush species was highest at $<5$ years since abandonment, lowest at 5-15 years, and then gradually increased again. The proportion of sedge and rush coverage was lowest at $<5$ years since abandonment, and then increased with the successional time (Fig.5B and Table

228

229 S5). The proportion of grass coverage in natural wetland (37.4\%) was higher than in abandoned

230

231 paddy fields, and with successional time it generally decreased. The proportion of grass coverage in the abandoned paddy fields was $20.2 \%, 12.5 \%$ and $12.1 \%$ respectively. The proportion of forb coverage was highest at $<5$ years since abandonment, and declined with time. After 5 years of abandonment, the proportion of sedge and grass coverage surpassed $50 \%$, becoming the dominant plant functional groups.

234 Figure 6 showed that the occurrence rate of wetland species increased with the time since 235 abandonment, and was higher in natural wetland than in abandoned paddy fields (Fig.6 and 236 Table S6).

\section{Discussion}

238 Following the abandonment of paddy fields, the vegetation undergoes a period of self239 reorganization during which the fields convert to marsh-type wetland by natural succession as 240 the species composition and dominance change over time. 
241

242

243

244

245

246

247

248

249

250

251

252

253

254

255

256

257

258

259

260

261

262

263

264

265

266

267

268

269

270

271

272

273

274

275

276

277

278

279

We focused on abandoned paddy fields originally converted from marshland dominated by herbaceous plants in a temperate region of China. At $<5$ years since abandonment, paddy weeds such as the annual E. crus-galli and B. tripartita grew rapidly and became pioneer species. The dominant tussock sedge $C$. rostrata had not yet appeared, probably owing to insufficient water availability and time. At 5-15 years, the annual wetland species Polygonum persicaria and $M$. keisak were dominant. At $>15$ years, however, the habitat had become more suitable for the development of wetland communities, and the community composition gradually evolved. The plant community was strongly dominated by C. rostrata and Scirpus orientalis, unlike at $<5$ years. Plant richness declined but the proportion of perennial plants increased, and the dominant species were very similar to those in natural wetlands, likely because our study sites were near natural wetlands.

A clear successional trajectory appeared whereby the assemblage dominance shifted from the annual grass weed E. crus-galli to the annual wetland species $P$. persicaria to the tussock sedge species $C$. rostrata. These results are consistent with the theories of self-design and of secondary succession: after a wetland is destroyed, the plant community could recover naturally through an obvious process of vegetation succession (Wang et al., 2012). We therefore conclude that the wetland vegetation at our study site was adaptable to the environment and could form a stable community after 15 years of natural recovery of abandoned paddy fields.

Plant composition clearly changes with age since abandonment (Cramer \& Hobbs, 2007). It is usually possible to distinguish three stages of succession in abandoned paddy fields: (1) the early stage is marked by the dominance of herbs; (2) the middle stage is marked by herbs and shrubs; and (3) the late stage is terminated by woodland plants (Lee and Kim, 2005). In our study region on a lowland plain, however, abandoned paddy fields were marked by various herbaceous communities, including tussock meadow, as climax communities. In this type of landscape, soil water levels tend to remain high, perhaps inhibiting establishment of woodland or forest (Shimoda \& Suzuki 1981; Yabe\& Numata 1984; Shimoda 1987, 1996). Previous studies of abandoned paddy fields in Japan (Shimoda \& Suzuki 1981; Shimoda 1987, 1996) and Korea (Kim \& Nam 1998; Lee et al., 2002) support a hydrosere model of succession. As the level of soil is progressively raised above the water level by the accumulation of humus and soil particles, the habitat becomes drier and vegetation passes from grassland to shrub and forest stages. Whether old fields further develop into shrubland or woodland depends on water conditions and surrounding vegetation (Dovčiak et al., 2005).

On the temperate lowland plain of the lower Tumen River, the Palaearctic and Holarctic chorological types made the highest contributions. Although species composition changed with the progression of secondary succession, the chorological composition of did not change conspicuously between species between probably owning to the similar geological history and ecological environment. We will consider the chorological spectra in large-scale areas in future research.

\section{Changes in plant diversity and evenness during secondary succession}


280 Our results showed a steady decrease in species richness and diversity with time. Both were 281 initially high because of the cultivation of many annual plants on drained wetlands. Some 282 surviving annual paddy weeds initially became dominant, outcompeting other species (Yamada, 283 2007), and some non-aquatic species were gradually eliminated owing to their inability to 284 compete in the aquatic environment. These results are consistent with other studies: Guo et al. 285 (2017) reported that plant diversity declined with time since abandonment; and Zhang et al. 286 (2004) and Wang et al. (2017) showed that community succession hastened initially and then 287 slowed. Other studies in marshland and coastal wetland ecosystems show that plant communities 288 dominated by few species tend to be more stable (Wang et al., 2012). The analysis of $\beta$-diversity 289 components revealed that species cover replacement seems to be the main process ruling

290

291

292

293

294

295

296

297

298

299

300

301

302

303

304

305

306

307

308

309

310

311

312

313

314

315

316

317

318

319 community assembly. Partitioning $\beta$-diversity was an informative approach to clarify the influence of land-use histories on plant communities. In community structure under natural secondary succession, species tend to replace each other most probably due to the sites conditions together with environmental factors.

Successional age affected the recovery and development of the vegetation. The first DCA axis was closely related to the time since abandonment, which is important for natural restoration of vegetation and ecosystems (Heshmatti \& Squires, 1997; Martinez et al., 2001). Thus, successional age was a key factor in controlling species composition and diversity(Zhang \& Dong, 2010). We conclude that the wetland vegetation in our study region is on a positive succession trajectory, and predict that the plant communities will eventually transition to stable communities in time. In the current study, natural wetland dominated by $C$. rostrata, S. orientalis and G. spiculosa as a reference selected in lower Tumen River Basin had its regional characteristics, such as low species diversity. Even though species diversity is low, it can still sustain itself without any intervention. The results showed that natural restoration could restore the dominant wetland species (C. rostrata, $S$. orientalis) like that in natural wetland. If species composition and other structural elements can be predicted, restoration practice projects could be focused on the conservation of key species (Walker \& Moral, 2003). Therefore, in this study area, during the wetland restoration, increasing these species could be considered as a positive indicator. If species composition and other structural elements can be predicted, restoration projects can focus on key species (Walker \& Moral, 2003).

\section{Changes in plant functional trait}

Natural succession on abandoned paddy field could restore the dominant communities like in natural wetland, but the goal of a full recovery of an ecosystem to a pre-disturbance state is often unrealistic (Walker et al., 2007). Our results documented that the time required for the recovery of abandoned paddy fields to be similar in composition and cover to natural wetland will greatly exceed 15 years. However, the proportion of species and coverage of plant functional groups was different between the abandoned paddy field and natural wetland. Early stages of plant community development in abandoned fields included a high coexistence of different plant functional types, which resulted in high species richness. Perennial sedges and grasses may have competitively suppressed other functional types, which resulted in low species richness in late 
320

321

322

323

324

325

326

327

328

329

330

331

332

333

334

335

336

337

338

339

340

341

342

343

344

345

346

347

348

abandoned paddy fields. Although forb species comprised most species richness in abandoned paddy fields, they could decline with increased dominance of perennial grass and sedge species.

In the late successional stage, plant communities were dominated by one to three sedge and grass species which accounted for $80 \%$ of the total plant coverage. Sedges and grass, as dominant vegetation groups in temperate marsh ecosystems, played a vital role in succession. In our study, we found that grass and sedge species rather than forbs were identified as key factors affecting succession of abandoned paddy fields on lower of Tumen River Basin. Therefore, monitoring progress toward restoration goals has tended to focus on the response of main plant functional groups. The changes in plant functional group could be used as a proxy to investigate the links between wetland species and restoration time on regional scales (Duckworth et al., 2000; Voigt et al., 2007). Special attention must be paid to those functional groups that showed differences in species richness and species coverage under natural succession, as these could be useful indicators of land-use history for managers of natural areas.

\section{Conclusions}

The vegetation ecological characteristics changed during secondary succession of marshland vegetation on the lower Tumen River. Communities initially dominated by annual weeds became dominated by Polygonum thunbergii and then Carex spp. with succession. The vegetation of the abandoned paddy fields recovered through natural succession. With the successional time, especially 15 years since abandonment, the species composition and diversity was becoming similar to the natural wetland, however, there were differences in plant functional groups. Although forb species compose most species richness in abandoned paddy fields, they can decline with increased dominance of perennial grass and sedge species. Although sedge and grass species compose lower species richness than other functional groups, they accounted for the majority of coverage. Our study was limited by the rough division of secondary succession phases due to our lack of information on the exact age of abandoned paddy fields. Therefore, we suggest that flexible time interval should be considered in future research. Future research should explore the ecological vegetation characteristics of marshlands along with natural succession driven by environmental perturbation.

\section{Acknowledgements}

We would like to thank Haicheng Zhou for his help with plant identification and fieldwork.

\section{References}

Alsterberg C, Roger F, Sundback K, Juhanson J, Hulth S, Hallin S, Gamfeldt L. 2017. Habitat diversity and ecosystem multifunctionality - The importance of direct and indirect effects. Science Advance 3(2):e1601475.

Anderson MJ, Ellingsen KE, McArdle BH. 2006. Multivariate dispersion as a measure of beta diversity. Ecological Letter. 9: 683-693. 
356

357

358

359

360

361

362

363

364

365

366

367

368

369

370

371

372

373

374

375

376

377

378

379

380

381

382

383

384

385

386

387

388

389

390

391

392

393

394

395

An SQ, Li HB, Guan BH, Zhou CF, Wang ZS, Deng ZF, Zhi YB, Liu YH, Xu C, Fang, S.B., Jiang, J.H., Li, H.L. 2007. China's natural wetlands: past problems, current status, and future challenges. Bio One 36:335-342.

Baselga A. 2012. The relationship between species replacement, dissimilarity derived from nestedness, and nestedness. Global Ecology and Biogeography. 21:1223-1232.

Brinson MM, Malvarez A.I. 2002. Temperate freshwater wetlands: types, status, and threats. Environmental Conservation 29(2):115-133.

Cao M, Zhang JH. 1997. Tree species diversity of tropical forest vegetation in Xishuangbanna, SW China. Biodiversity and Conservation 6:995-1006.

Cho YC, Lee SM, Lee CS. 2018. Floristic composition and species richness of soil seed bank in three abandoned rice paddies along a seral gradient in Gwangneung Forest Biosphere Reserve, South Korea. Journal of Ecology and Environment. 42:12.

Costanza, R, d'Arge R, de Groot, R., Farber S, Grasso M, Hannon B, Limburg K, Naeem S, O'Neill RV, Paruelo J, Raskin RG, Sutton P, van den Belt M. 1997.The value of the world's ecosystem services and natural capital. Nature. 387: 253-260.

Cramer VA, Hobbs RJ. (eds.) 2007. Old fields: dynamics and restoration of abandoned farmland. Island Press, Washington.

Cramer VA, Hobbs RJ, Standish RJ. 2007. What's new about old fields? Land abandonment and ecosystem assembly. Trends in Ecology and Evolution. 23: 104-112.

Cui BS, Yang ZF 2001. Benefit valuation of typical wetlands in Jinlin province. Resources Science 23(3) 55-61. [In Chinese with English abstract]

Davidson, NC. 2014 How much wetland has the world lost? Long-term and recent trends in global wetland area. Marineand Freshwater Research. 65: 934-941.

Dovčiak M, Frelich LE, Reich PB. 2005. Pathways in old-field succession to white pine: seed rain, shade, and climate effects. Ecological Monographs. 75(3):363-78.

Duckworth JC, Kent M, Ramsay PM. 2000. Plant functional types: an alternative to taxonomic plant community description in biogeography? Progress in Physical Geography 24: $515-54$.

Gao WY, Zhu CF Wang YS. 2000. Analysis on Characteristic of hydrology and meteorology for Tumen Jiang Basin. Jilin Water Resources. 12: 22-24. [In Chinese with English abstract]

Guo J, Jiang HB, Bian HF, Sheng L, He CG, Gao YZ. 2017. Natural succession is a feasible approach for cultivated peatland restoration in Northeast China. Ecological Engineering. 104:39-44.

Heshmatti G, Squires VR. 1997. Geobotany and range ecology: a convergence of thought? Journal of Arid Environments. 35:395-405.

Kang CH, Zhang YL, Wang ZF, Liu LS, Zhang HM, Jo YG. 2017. The driving force analysis of NDVI dynamics in the trans-boundary Tumen River Basin between 2000 and 2015. Sustainability. 9(12): 1-19.

Katinas L, Morrone J, Crisci J.1999. Track Analysis Reveals the Composite Nature of the Andean Biota. Australian Journal of Botany. 47: 111-130. 
396

397

398

399

400

401

402

403

404

405

406

407

408

409

410

411

412

413

414

415

416

417

418

419

420

421

422

423

424

425

426

427

428

429

430

431

432

433

434

Kennedy G, Mayer T. 2002. Natural and constructed wetlands in Canada: an overview. Water Quality Research Journal of Canada. 37(2), 295-325.

Kim JW, Nam HK. 1998. Syntaxonomical and synecological characteristics of rice field vegetation. Korean Journal of Ecology. 21: 203-215.

Krebs C. 1989. Ecological Methodology. Harper Collins Publishers. U.S.A.

Kusumoto Y, Ohkuro T, Ide M.2005. The relationships between the management history and vegetation types of fallow paddy field and abandoned paddy fields - Case study of Sakuragawa and Kokaigawa River basin in Ibaraki prefecture. Journal of Rural Planning Association. 7: 7-12. [In Japanese with English abstract]

Lee, CS, You YH, Robinson GR. 2002 Secondary succession and natural habitat restoration in abandoned rice fields of central Korea. Restoration Ecology. 10: 306-314.

Lee KS, Kim JH. 1995 Seral Changes in Floristic Composition during Abandoned Field Succession after Shifting Cultivation. Korean Journal of Ecology 18(2): 275-283.

Lee SM.2006. Secondary Succession and Seed Bank Structure of Abandoned Rice Paddy Field, and its Ecological Restoration. Thesis, Seoul Women's University.

Martinez, ML, Vazquez G, Sanchez CS 2001. Spatial and temporal variability during primary succession on tropical coastal sand dunes. Journal of Vegetation Science 12: 361-372.

Magee TK, Ernst TL, Kentula ME, Dwire KA. 1999. Floristic composition of freshwater wetlands in an urbanizing environment. Wetlands. 19: 517-534.

Magurran AE. 1988 Ecological Diversity and its Measurement. Croom Helm, London, 179.

Margalef R. 1958. Temporal succession and spatial heterogeneity in phytoplankton. In: Perspectives in Marine Biology, Buzzati-Traverso (ed.), Univ. Calif. Press, Berkeley, 323347.

Mitsch WJ, Gosselink JG. 2015. Wetlands (5th ed.). John Wiley \& Sons, New York, USA.

Oksanen J, Blanchet G, Kindt R, Legendre P, Minchin PR, O'Hara RB, Simpson GL, Solymos P, Stevens MHH, Wagner H. 2017. Vegan: Community Ecology Package. R package version 3.3.2. Available: http://cran.r-project.org/package=vegan.

Pielou EC. 1966. The measurement of diversity in different types of biological collections. Journal of Theoretical Biology. 13: 131-144.

Podani, J. 2001. SYN-TAX 2000. Computer Programs for Data Analysis in Ecology and Systematics. User's Manual. Budapest: Scientia.

Podani J, Schmera D. 2011. A new conceptual and methodological framework for exploring and explaining pattern in presence-absence data. Oikos 120: 1625-1638.

Podani J, Ricotta C, Schmera D. 2013. A general framework for analyzing beta diversity, nestedness and related community-level phenomena based on abundance data. Ecological Complexity 15: 52-61.

Raunkiaer C. 1934. The life forms of plants and statistical plant geography. The Clarendon Press, Oxford.

Ruto WKS, Kinyamario JI, Ng'etich NK, Akunda E, Mworia JK. 2012. Plant species 
435

436

437

438

439

440

441

442

443

444

445

446

447

448

449

450

451

452

453

454

455

456

457

458

459

460

461

462

463

464

465

466

467

468

469

470

471

472

473

474

composition of two wetlands in the Nairobi National Park, Kenya. Journal of Wetland Ecology. 6:07-15.

Shimoda M. 1987. The reedswamp and sedge marsh vegetation of the Oasa Basin, Hiroshima Prefecture, western Japan. Hikobia. 10: 21-29.

Shimoda M. 1996. Abandoned rice field vegetation and its evaluation. A case study of wet abandoned rice field vegetation in Hiroshima Prefecture. Vegetation Science 13: 37-50.

Shimoda M, Suzuki H. 1981. Vegetation of fallow rice fields in the Saijo Basin, Hiroshima Prefecture, Japan, Japan. Hikobia Supplement. 1: 321-339.

Shannon CE, W Wiener 1949. The mathematical theory of communication. Urbana, University of Illinois Press.

Sun, Z. G., Liu, J. S., Li B. 2006. The actuality, problems and sustainable utilization countermeasures of wetland resources in China, Journal of Arid Land Resources and Environment 20: 83-88. [In Chinese with English abstract]

Taft JB, Kron ZP. 2014. Evidence of species and functional group attrition in shrub-encroached prairie: implications for restoration. The American Midllan. Natturalist. 172: 252-265.

Takanose Y, Ishida S, Kudo N, Kamitani T. 2013. Effects of tillage and irrigation on the occurrence and establishment of native wetland plant species in fallow paddy fields. Paddy and Water Environment.11: 45-58.

Takhtajan, AL. 1986. The Floristic Regions of the World. UC Press, Berkeley.

Voigt W, Perner J, Jones TH. 2007.Using functional groups to investigate community response to environmental changes: two grassland case studies. Global Change Biology.. 13: 17101721.

Walker, LR, Moral R 2003 Primary succession and Ecosyste rehabilitation.Cambridge University Press Cambridge, United Kingdom 427.

Wang GD, Middleton B, Jiang M 2013 Restoration potential of sedge meadows in handcultivated soybean fields in Northeastern China. Restoration Ecology. 21: 801-808

Wang GD, Wang M, Lu XG, Jiang M 2017 Duration of farming is an indicator of natural restoration potential of sedge meadows. Scientific Reports.7:10692.

Wang XH, Yu JB, Zhou D, Dong HF, Li YZ, Lin QX, Guan B, Wang YL. 2012. Vegetative ecological characteristics of restored reed (Phragmites australis) wetlands in the Yellow River Delta. China. Environmental Management. 49 (2): 325-333.

Wang, ZM, Wu, JG, Madden M, Mao DH. 2012. China's wetlands: conservation plans and policy impacts. $A M B I O$ 41:782-786.

Yamada S, Okubo S, Kitagawa Y, Takeuchi K. 2007 Restoration of weed communities in abandoned rice paddy fields in the Tama Hills, central Japan. Agriculture,. Ecosystem and Environment. 119: 88-102.

Yamanaka S, Akasaka T, Yabuhara Y, Nakamura F. 2017. Influence of farmland abandonment on the species composition of wetland ground beetles in Kushiro, Japan. Agriculture Ecosystem and Environment. 249: 31-37.

Zedler JB, Kercher S. 2005. Wetland resources: status, trends, ecosystem services, and 
475 restorability. Annual Review of Environmentand Resources. 30: 39-74.

476 Zhang J, Dong Y. 2010. Factors affecting species diversity of plant communities and the 477 restoration process in the loess area of China. Ecological. Engineering. 36(3):345-350.

478 Zhang H, John R, Peng Z, Yuan J, Chu C, Du G, Zhou S . 2012. The relationship between 479 species richness and evenness in plant communities along a successional gradient: a study 480 from sub-alpine meadows of the eastern Qinghai-Tibetan Plateau, China. PLoS One 7(11): 481 e49024.

482 Zheng, XJ, Sun P, Zhu WH, Xu Z, Fu J, Man WD, Li HL, Zhang J, Qin L. 2017. Landscape 483 dynamics and driving forces of wetlands in the Tumen River Basin of China over the past 50 $484 \quad$ years. Landscape and Ecological Engineering. 2013, 237-250.

485 Zhu WH, Guo YL, Sun P, Miao CY, Cao GL. 2012. Wetland ecosystem health assessment of 486 487 the Tumen River downstream, Acta Ecologica. Sinica 32(21):6609-6618. [In Chinese with English abstract] 


\section{Table $\mathbf{1}$ (on next page)}

Summary of the attributes of the sampling plots for the abandoned paddy wetlands in the different restoration years in downstream of Tumen River Basin, Northeast China. 
1

\begin{tabular}{lrrrrrr}
\hline \multirow{2}{*}{ Items } & \multicolumn{3}{c}{ Years since abandonment } & \multirow{2}{*}{$\begin{array}{c}\text { Natural } \\
\text { wetland }\end{array}$} & Total \\
\cline { 2 - 4 } & $\mathrm{Ab}<5$ & $5<\mathrm{Ab}<15$ & $\mathrm{Ab}>15$ & & 11 & 26 \\
\hline Site number & 6 & 5 & 4 & 55 & 130 \\
Sample number & 30 & 25 & 20 & 55 & 130 \\
Sample area $\left(\mathrm{m}^{2}\right)$ & 30 & 25 & 20 & 24 & 39 \\
Family number & 22 & 20 & 15 & 38 & 74 \\
Genera number & 40 & 33 & 25 & 47 & 114 \\
Species number & 62 & 42 & 35 & 83 & 77 \\
Plant coverage (\%) & 85 & 67 & 74 & &
\end{tabular}

2 


\section{Figure 1 (on next page)}

Proportions of chorological spectrum composition in paddy fields of different ages since abandonment (Ab, years) and in natural wetlands (NAT) in the lower Tumen River, northeast China.

Abbreviations: Ori $=$ Oriental, Aus $=$ Australian, Afro $=$ Afrotropical. 


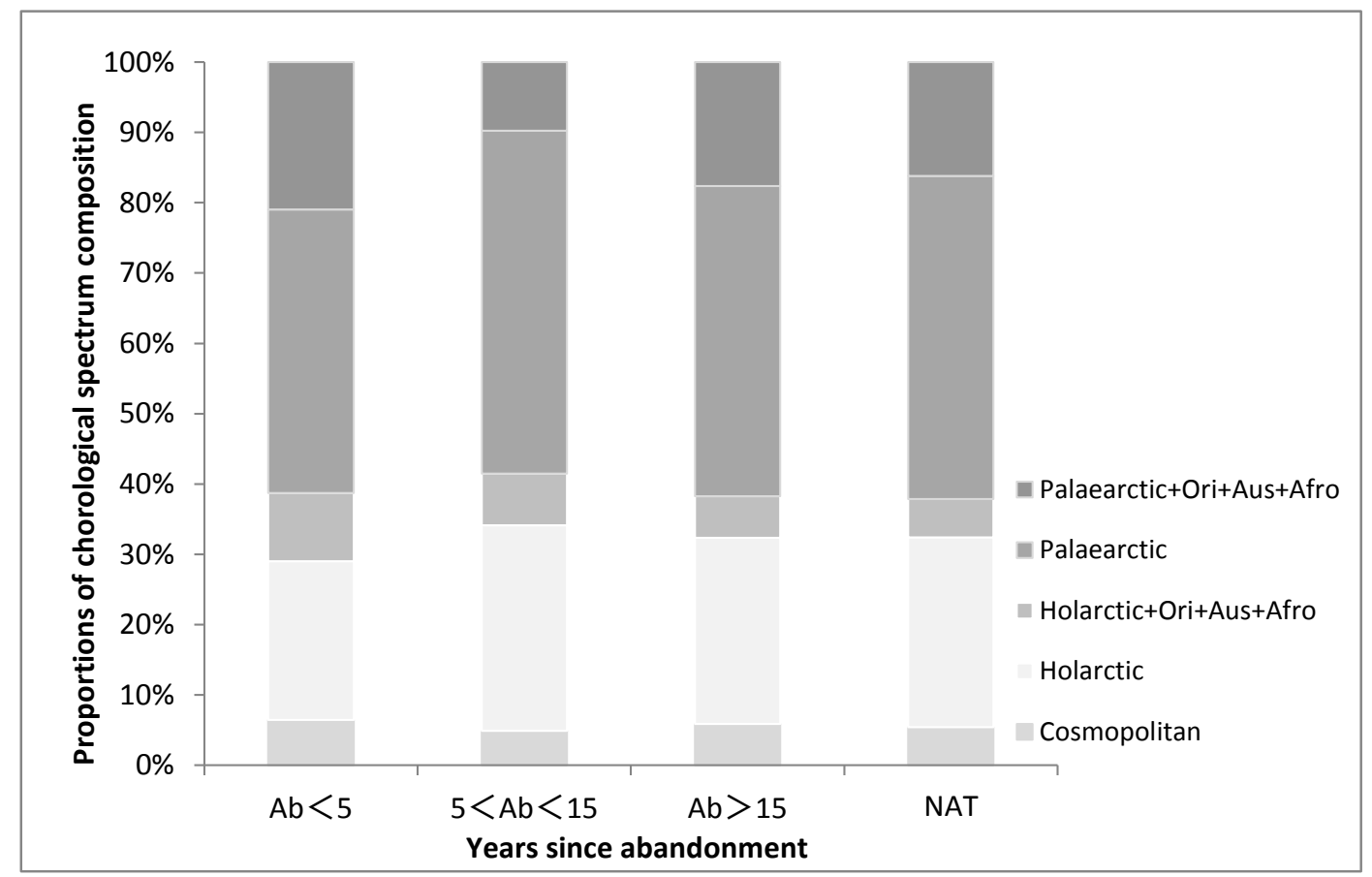




\section{Figure 2 (on next page)}

Richness index (R), Shannon-Wiener diversity index (H), Simpson's index (D) and Pilou's evenness index (J) of plant communities in paddy fields at different times since abandonment and in natural wetlands.

The vertical bar is SD and the letters represent significant differences from post hoc Tukey tests (P口 0.05). 

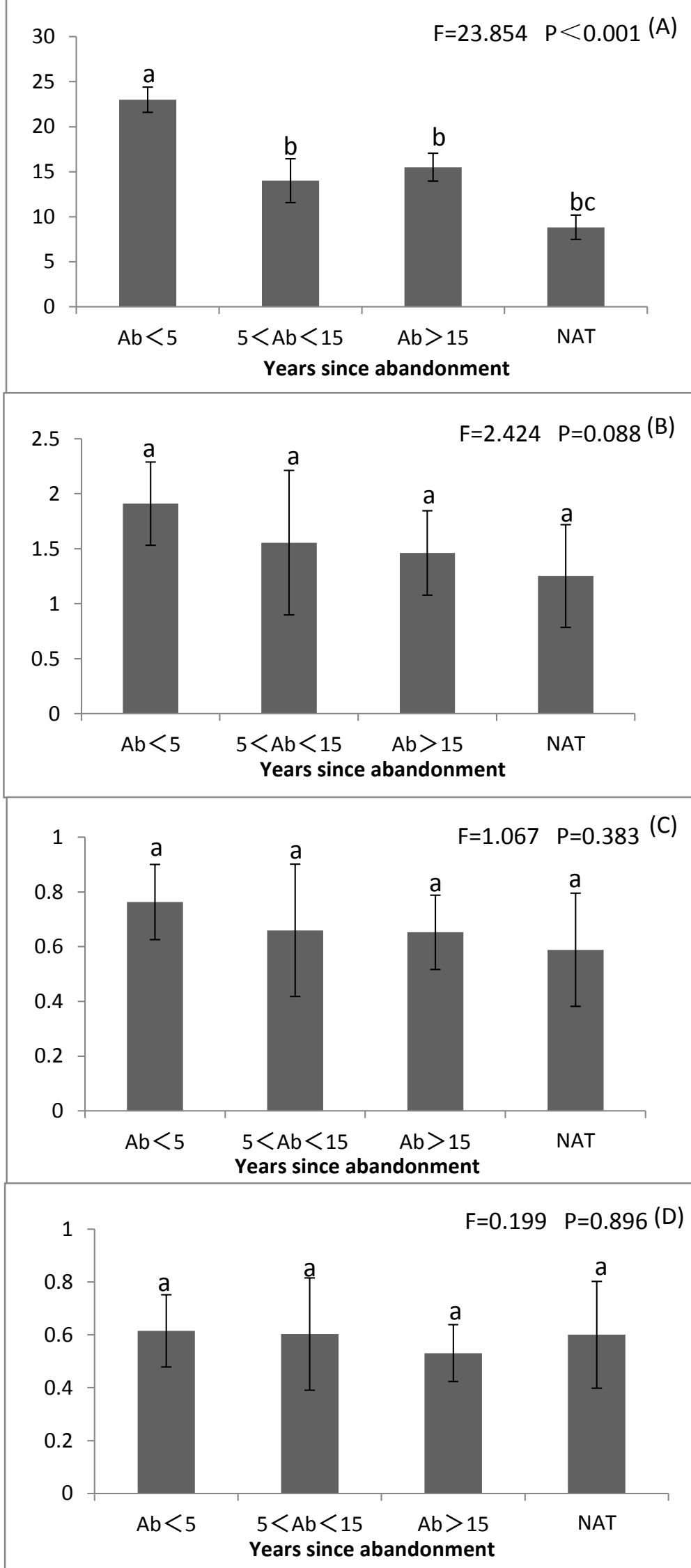
Figure 3 (on next page)

SDR abunSimplex ternary plots for the cover date of different abandoned paddy fields. S: Ružička similarity; R: abundance replacement; $D$ : abundance richness difference. (A): -5 year abandoned paddy fields; (B):5-15 year abandoned paddy fields; (C):15- yea 

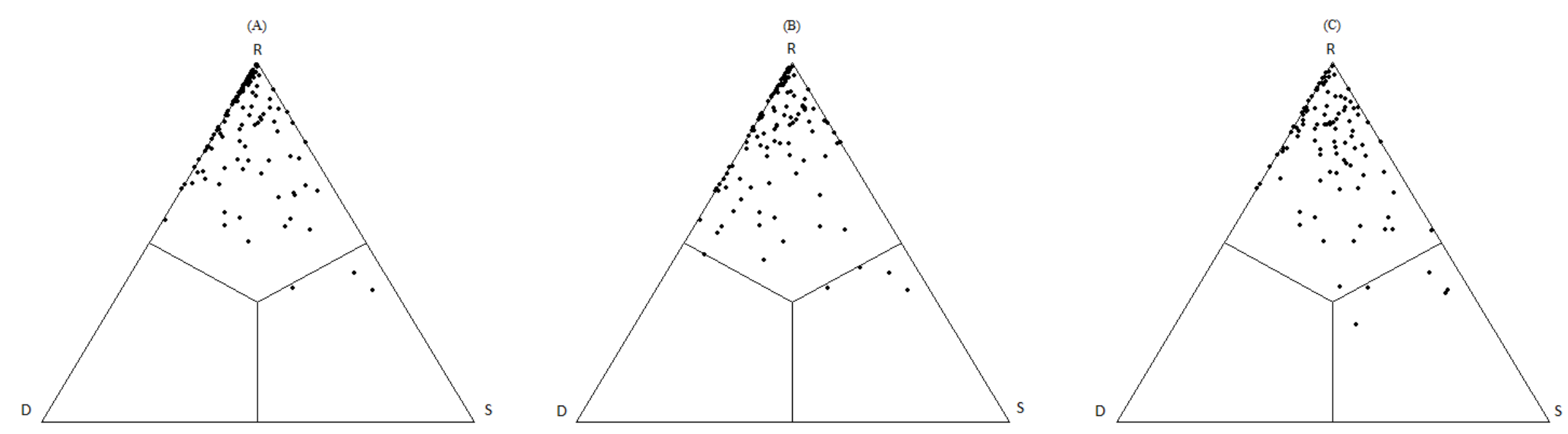
Figure 4(on next page)

DCA ordination of species percentage cover showing samples. Axes 1 and 2 accounted for 0.8687 and 0.7182 , respectively, of total variation in data.

Ellipses were drawn to group the samples by abandoned ages in paddy fields and reference natural wetland. 


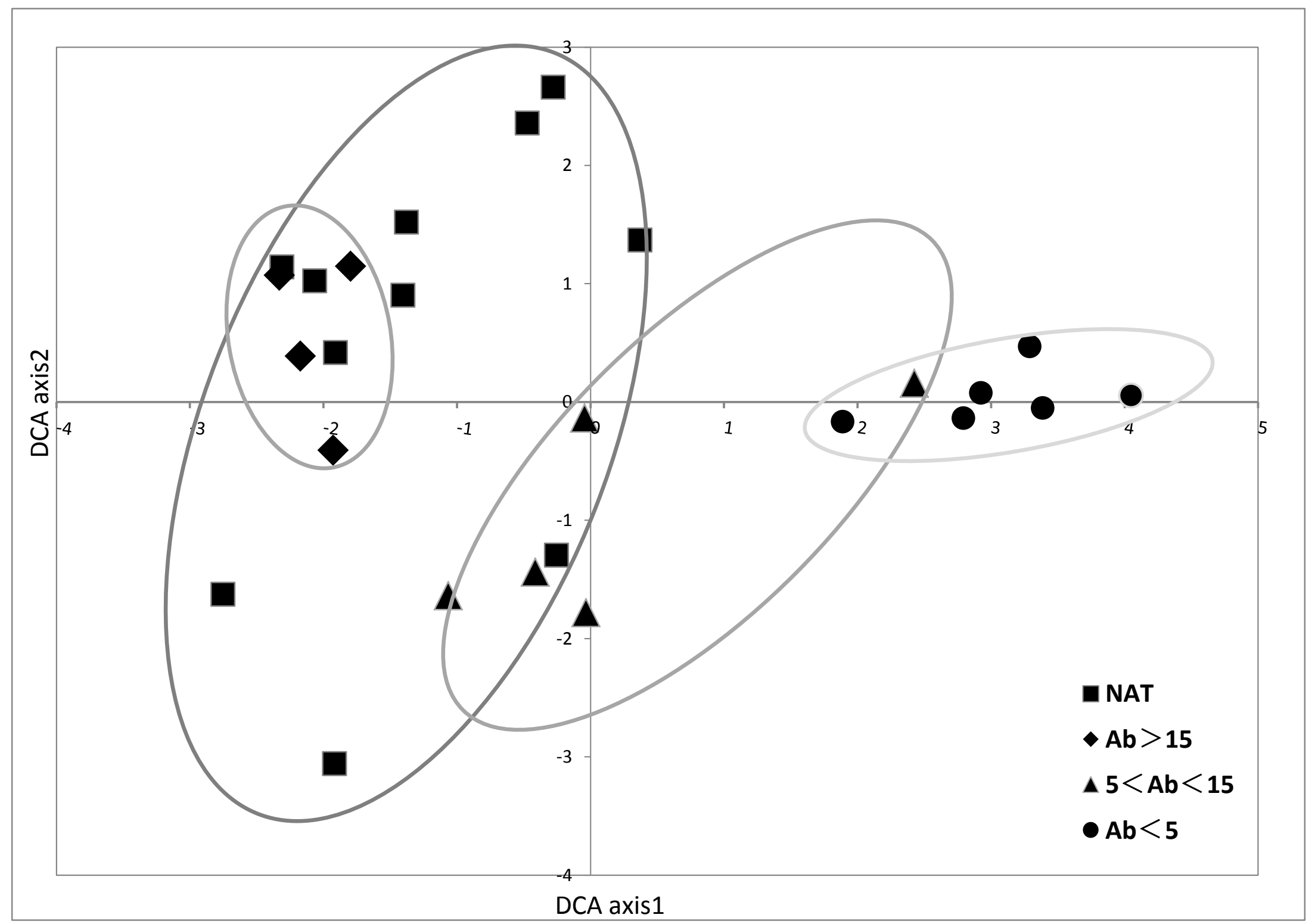




\section{Figure $\mathbf{5}$ (on next page)}

Proportions of species and coverage of three functional groups in paddy fields at different times since abandonment and in natural wetlands. 


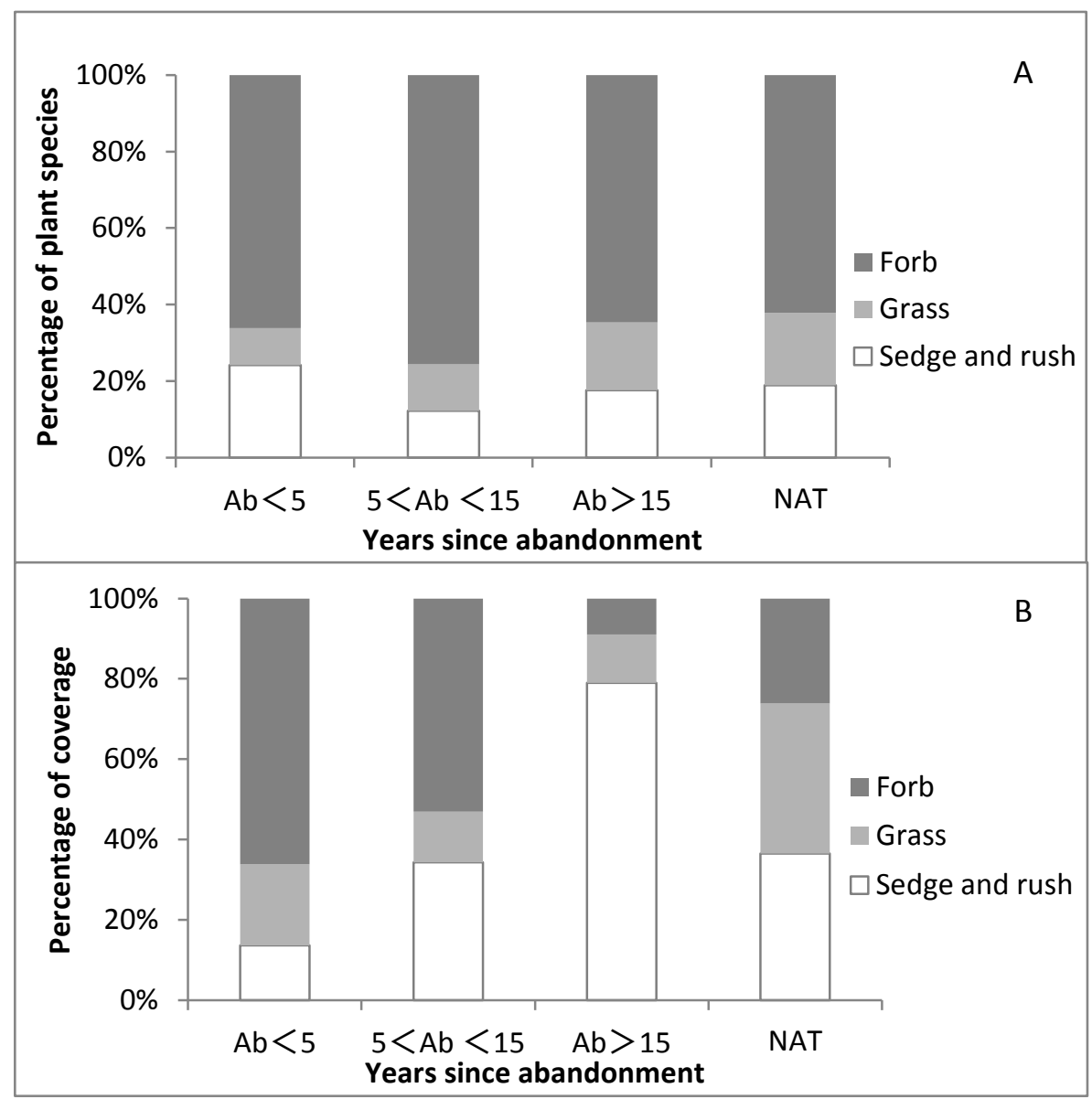


Figure $\mathbf{6}$ (on next page)

Occurrence rate of wetland species and Non-wetland species 


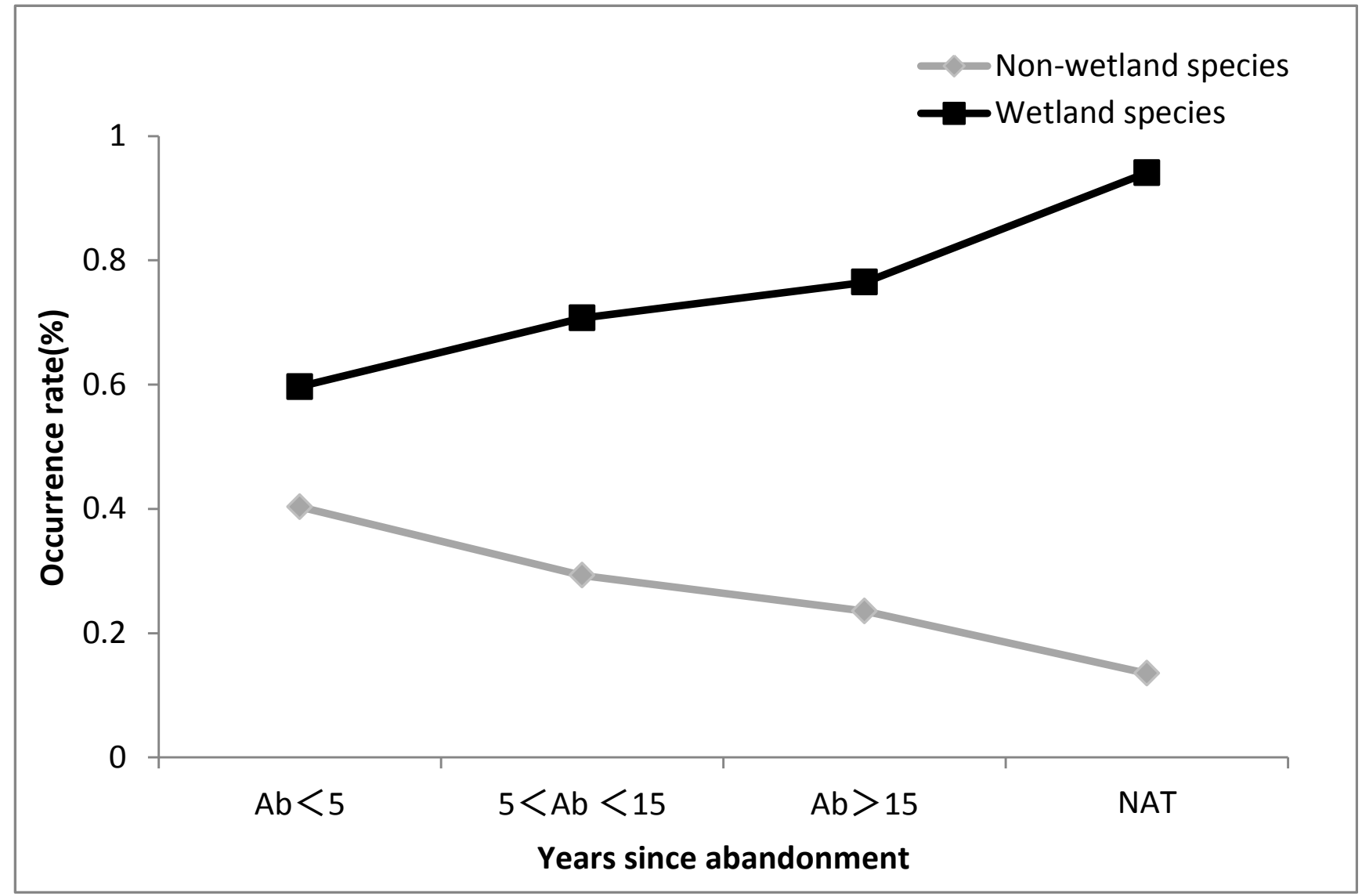

